\title{
Effect of Wind Farm Noise on Local Residents' Decision to Adopt Mitigation Measures
}

\author{
Anabela Botelho ${ }^{1}$, Pedro Arezes ${ }^{2, *}$ (D), Carlos Bernardo ${ }^{3,4}$, Hernâni Dias ${ }^{4}$ and \\ Lígia M. Costa Pinto ${ }^{5}$ \\ 1 Department of Economics, Management, Industrial Engineering, and Tourism, University of Aveiro, and \\ GOVCOPP, 3810-193 Aveiro, Portugal; anabela.botelho@ua.pt \\ 2 ALGORITMI Research Center, University of Minho, 4800-058 Guimarães, Portugal \\ 3 Institute of Polymers and Composites/I3N, University of Minho, 4800-058 Guimarães, Portugal; \\ cbernardo@dep.uminho.pt \\ 4 PIEP-Innovation in Polymer Engineering, 4800-058 Guimarães, Portugal; hernadias@gmail.com \\ 5 NIMA-Department of Economics, University of Minho, 4710-057 Braga, Portugal; pintol@eeg.uminho.pt \\ * Correspondence: parezes@dps.uminho.pt; Tel.: +351-253-510340
}

Received: 3 May 2017; Accepted: 6 June 2017; Published: 11 July 2017

\begin{abstract}
Wind turbines' noise is frequently pointed out as the reason for local communities' objection to the installation of wind farms. The literature suggests that local residents feel annoyed by such noise and that, in many instances, this is significant enough to make them adopt noise-abatement interventions on their homes. Aiming at characterizing the relationship between wind turbine noise, annoyance, and mitigating actions, we propose a novel conceptual framework. The proposed framework posits that actual sound pressure levels of wind turbines determine individual homes' noise-abatement decisions; in addition, the framework analyzes the role that self-reported annoyance, and perception of noise levels, plays on the relationship between actual noise pressure levels and those decisions. The application of this framework to a particular case study shows that noise perception and annoyance constitutes a link between the two. Importantly, however, noise also directly affects people's decision to adopt mitigating measures, independently of the reported annoyance.
\end{abstract}

Keywords: wind farms; noise annoyance; mitigation measures; sound pressure levels; environmental impacts

\section{Introduction}

Wind has been used as a power source almost since the rise of human civilization. Later, in the most advanced economies, its intermittent and (then) unpredictable nature, made it uncompetitive with other power sources, namely those based on steam. Recently, due to technological developments, its use, especially for electricity generation, has been increasing worldwide [1]. Nowadays, wind power is considered to be an environmentally-friendly energy source, technologically mature and economically competitive.

However, the installation of wind turbines (WTs) has consequences in the use of land and may have other negative side effects. Amongst these, the effect of noise on human health and annoyance is of paramount importance. Although the measurement of annoyance is highly subjective, the concept can be understood as a cause of irritation or vexation; a nuisance. A good definition is provided by Guski et al. [2], namely "a multifaceted concept, covering mainly immediate behavioral noise effects aspects, like disturbance and interfering with intended activities". In fact, WT noise can be easily perceived (and be an annoyance) even for low sound pressure levels, making it generally incongruous with background noise [3]. As a consequence, it may be a problem for local communities, and one of the reasons they often object to the installation of new wind farms in their vicinity. Indeed, after lack 
of knowledge on environmental issues related to renewable energies, this is the second major cause of opposition to the implementation of such projects [4]. For example, evidence rendered in a public hearing in New Zealand revealed that most people living close to WT are able to perceive the noise generated by them, although, as expected, the effect decreased with distance [5]. Another disclosure of this hearing was that people were more annoyed with turbine noise during the night period, although its measured characteristics were quite similar to those determined during the day. As a consequence, some respondents decided to sleep with earplugs or even to improve their homes' sound insulation. These findings are consistent with other studies reporting that people living near wind farms complain of a variety of negative physiological and psychological symptoms [6]. In certain cases, these symptoms are sufficiently serious to force them to modify their homes (e.g., implementation of sound insulation measures) to reduce the intrusive noise or even, in the extreme, to abandon their residences $[7,8]$.

The literature on the effects of wind turbine noise on the health and annoyance of exposed people, which has grown significantly since 2000, has been the subject of various recent reviews. The first one, by Jeffery et al. [9], concluded that there is sufficient evidence to believe that people exposed to audible WT noise experience negative effects in their physical, mental and social well-being and that those symptoms can result from the ensuing annoyance. Schmidt and Klokker [10] also report that in the literature there is evidence of a dose-response relationship between wind turbine noise, sleep disturbance and possibly even psychological distress, linked to noise annoyance. A large study involving 1238 households in Southern Ontario and Prince Edward Island published in 2014 by the Government of Canada [11], also concluded that proximity to wind farms is associated with annoyance and, less consistently, with sleep disturbance and poorer quality of life. Onakpoya et al. [12] reviewed published data on the association between exposure to wind turbine noise, sleep disturbance and quality of life. Globally, they concluded that there is some evidence for a causal relationship between increased odds of annoyance and sleep problems, although individual attitudes could influence the type of response. On the other hand, an extensive and recently published study commissioned by the Australian government on the impact of wind farms on human health concluded that there is no reliable or consistent evidence that proximity to wind farms, or wind farm noise directly causes health effects [13]. That conclusion is partially contradicted by a study in Canada [14] that found that there is sufficient evidence to establish a direct causal relationship between exposure to wind turbine noise and annoyance but not with sleep disturbance. However, an indirect (via annoyance) causal relationship might exist with the latter. A recent study by Jalali et al. [15], using a prospective cohort design, presented noise and sleep measurements done before and after installation of WT. It showed that participants reported poorer sleep quality if they had a previous negative attitude to WT, if they were concerned with property devaluation, or if they could see turbines from their properties. Thus, although the controversy about the effects of WT noise on human health is far from over, the current overall literature seems to indicate that it can affect, to a greater or lesser extent, the wellness of the people exposed. The literature also seems to suggest that annoyance plays a mediator role in that relationship.

Furthermore, in addition to probable adverse health effects and reduced quality of life, exposed individuals face the financial burden of having to take measures to solve, or at least mitigate, the effects of the unwanted sound caused by WT. While such financial burden may constitute an important component of the external economic costs borne by those living close to wind farms, no study to date has empirically evaluated the actual effect of measured WT noise on individuals' necessity to modify their homes. Thus, in the present study, we address this issue by proposing a conceptual framework relating those sound levels with individual homes' noise-abatement interventions, and assessing the role that self-reported annoyance (a proxy for noise perception), both at indoors and outdoors settings, plays in that relationship. This is done by applying structural modeling and estimation techniques that are appropriate to empirically test the proposed framework given the type of data collected. The described analysis was restricted to noise exposed populations and did not include any comparison with other populations not exposed to WT noise. In fact, it was assumed that in rural settings such 
as the one under study, far from alternative strong noise sources, there is no clear need to adopt any noise-abatement interventions. Conversely, the study considers subjects that decided to take noise abatement measures, and those that did not, the latter providing a population control group.

The remainder of the paper is structured as follows: Section 2 presents the conceptual framework, outlines the procedures used in data collection, and provides details about the econometric specification and estimation strategy. Section 3 reports and discusses the empirical results, and Section 4 concludes.

\section{Materials and Methods}

\subsection{Conceptual Framework}

Annoyance is the most commonly reported problem caused by wind turbine noise exposure. In severe forms it may affect individuals' health and well-being thereby contributing to the burden of this environmental noise [16]. Thus, noise-induced annoyance has often been the primary response variable used in social surveys to evaluate the health effects of noise on people living close to WT, even if the relationship with noise characteristics are not yet well explained or understood [17]. While the association between wind turbine noise and annoyance is generally accepted, controversy remains about the importance of this association. If acoustic factors such as sound pressure levels (SPL) only partly influence individuals' annoyance response, their public health implications should be small. In addition, annoyance is a subjective psychological concept, and the fact that noise causes annoyance does not necessarily mean that it significantly impairs individuals' health. Legally, there is case law evidence that environmental hazards need to attain a minimum level of disturbance (resulting in a sufficiently severe injury to individuals' property, their private or family life) in order to justify authorities' implementation of precautionary, protective, or compensatory measures [18]. Along with annoyance, revealed preference of individuals' seeking health-related restoration or well-being by temporarily or permanently leaving their residences has also been identified as a criterion for diagnosis of "probable adverse health effects" in the vicinity of WT, the latter being singled out as a distinguishing factor between adverse health effects due to WT versus independent causes [19]. Thus, revealed preference information concerning individuals' reactions to wind turbine noise allows a better assessment, not only of the causal relationship between noise and health/well-being outcomes, but also of the severity of the burden. Indeed, studies focusing on adverse event reports consider individuals' willingness to spend resources on retrofitting their houses to reduce noise as an indication of both individuals' conviction regarding the causal pathway between WT noise and disease and of the intensity of their noise-induced suffering [20]. Moreover, establishing a link between annoyance, an individual's subjective feeling, and his actions to prevent it, may constitute a significant contribution to the acceptability of annoyance studies' results. In line with these considerations, a conceptual framework relating noise exposure to the decision to take retrofitting measures is presented in Figure 1.

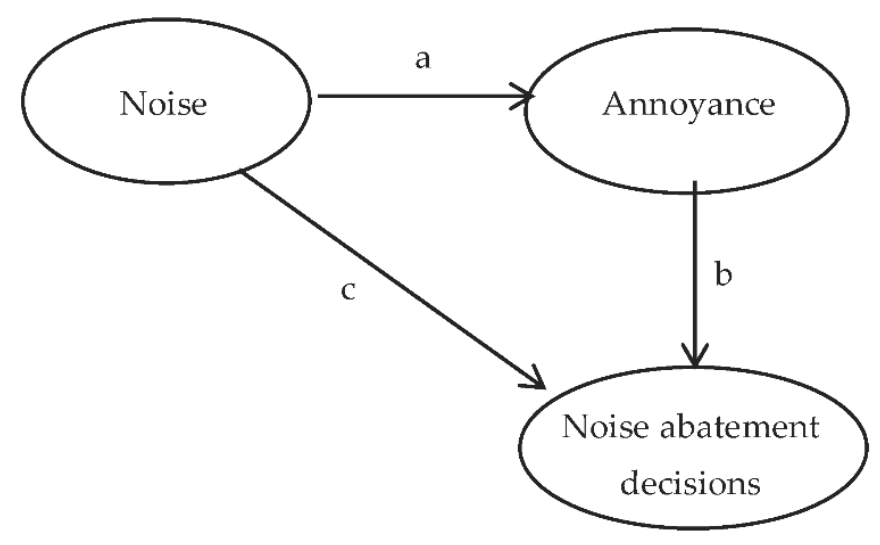

Figure 1. Exposure-response relationship for wind turbine noise. 
The conceptual framework presented in Figure 1 posits that the overall impact of wind turbine noise is quantified based on the relationship between noise dose and response, the latter measured by revealed preference information describing individuals' willingness to spend resources on retrofitting their houses. Considering the diagram, there is also some direct effect between noise and individuals well-being in terms of annoyance. In turn, annoyance may lead to forced behavioral responses with the aim of decreasing the overall noise burden. Thus, the subjective appraisal of annoyance mediates the relationship between noise levels and the outcome, as represented by the indirect effect $b$. Whether noise annoyance, as subjectively evaluated, fully or only partly mediates the proposed exposure-response relationship depends on the significance of path $c$. If the entire noise effect goes through annoyance, then path $c$ takes the value zero, and there is full mediation. If the noise level acts as an independent contributor to the revealed outcome variable, irrespective of annoyance, then the effect $c$ will be nonzero, and there is partial mediation.

\subsection{Data Collection}

The present work was carried out in the Fafe Highlands (Terras Altas de Fafe) wind farm in the north of Portugal. This wind farm is located in the municipalities of Fafe and Celorico de Basto, in a mountain area, $851 \mathrm{~m}$ height on average. The farm is composed of $53 \mathrm{WT}$, corresponding to $106 \mathrm{MW}$ of total installed capacity. The annual production is estimated at circa $210 \mathrm{GWh}$ (for an equivalent of $2000 \mathrm{~h}$ of full load/year). The turbines are all dimensionally identical, with a $67 \mathrm{~m}$ height tower and a $87 \mathrm{~m}$ rotor diameter. A-weighted SPL measured near the facades of the houses located in the periphery of the farm were chosen as measuring standards. The results of these measurements were cross-checked with the answers to a questionnaire on noise perception collected from the residents of those houses.

\subsubsection{Data Collection Procedures}

Considering the research objectives, the planned research was carried out according to the following protocol:

(1) Characterization of the location of wind farms relatively to nearby populations; this characterization was based on a specific typological classification, considering, amongst other factors, the visibility of the turbines;

(2) Direct measurement of the SPL in the selected areas, with a view to assess the acoustic impact of the wind farms. In the current study, noise levels were measured in different zones within the exposed villages, and the corresponding values were used as a proxy indicator (and not a precise noise dose or exposure level) of the noise exposure of the inhabitants of that same zone;

(3) Development of a questionnaire on noise perception based on previous ones developed by Pedersen and Waye [21] properly adapted to the Portuguese situation;

(4) Application of the questionnaire to the residents of chosen villages.

\subsubsection{Sound Measurements}

The sound measurements were carried out in the villages of Campo Dianteiro (CD), Lagoa (L), Várzea Cova (VC) and Vila Pouca (VP), all in the immediate vicinity of the wind farm (Figure 2).

Inspection of Figure 2 allows a rough estimate of the distance from the villages/dwellings to the $\mathrm{WT}$, which ranges from 250 to $1000 \mathrm{~m}$. In each village, two different areas were defined corresponding to a "high" and a "low" point (as most of the villages have a steep topography) and the measurements were grouped accordingly. The determinations were made using a sound level meter Bruel\&Kjaer model 2260 type 1, equipped with a tripod. The equipment was positioned at a $1.2 \mathrm{~m}$ of height from the ground and no closer than $4.0 \mathrm{~m}$ from the facades, in order to avoid reflection effects. In each location, the ' $A$ ' frequency equivalent continuous sound pressure level (LAeq) was registered considering a 5 min measurement period, during which the background noise was monitored. This was necessary to 
avoid the inclusion of "external" irrelevant noise events not related to the WT. When one such event occurred, as for example, the sudden barking of a dog or the passing of a car, the measurement was stopped and the event eliminated. During the measurements, the wind speed was also assessed and registered and found to be consistently low, i.e., less than $2 \mathrm{~m} / \mathrm{s}$. It is also important to highlight that some sporadic impulsive characteristics were sometimes detected, mainly from the existent background noise, which seemed not to affect the WT registered overall SPL.

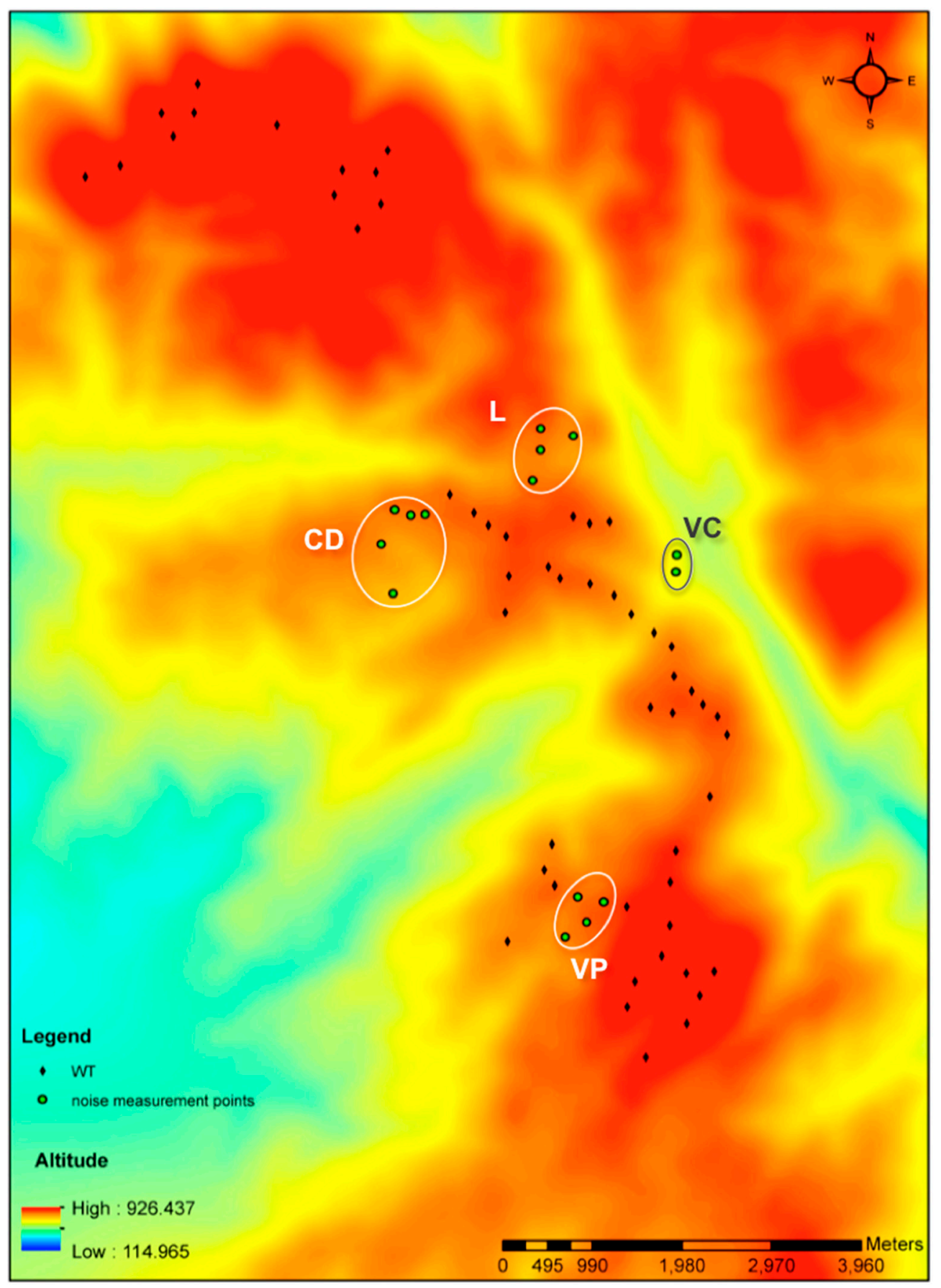

Figure 2. Map of the wind farm studied with the corresponding measurement locations (black dots: Wind Turbines; green circles: dwellings at the measurements' locations, L: Lagoa, CD: Campo Dianteiro, VC: Várzea Cova, VP: Vila Pouca). 


\subsubsection{Questionnaire}

The questionnaire (Appendix A), adapted from the one originally developed by Pedersen and Waye [21] was organized in three sections with distinct types of questions. In Section I, the questions aimed at assessing how the respondents reacted to their environment, and detecting any respondent bias that could affect and skew the answers in Section II. The questions in Section II aimed at assessing respondents' perception of WT noise. Finally, Section III included questions regarding personal data of the respondents, as well as the data on the implementation of mitigation measures in their dwellings, either before or after the installation of the wind farm. The questionnaire was administered by the researchers to the inhabitants of the four villages under study.

The questionnaire targeted the inhabitants of the villages located close to the WT and it was applied to all the people that were living there and available to respond to the questionnaire. As the villages included in the study were quite small and dispersed, the questionnaires were distributed in person, by hand, to adult residents in dwellings potentially exposed to WT noise, who showed willingness to participate in it. In the beginning of the interviews, its nature and objectives were thoroughly explained to the potential respondents and their informed consent obtained. Given that the real number of the villages' inhabitants at the time the questionnaire was presented was unknown, no answer rates were computed in this study.

\subsection{Statistical Methods}

For statistical purposes, the preceding conceptual framework was operationalized through the following path, or two-equation structural model:

$$
\begin{gathered}
R_{i}=f_{1}\left(S P L_{i}, A_{i}, X_{1 i}\right) \\
A_{i}=f_{2}\left(S P L i, X_{2 i}\right)
\end{gathered}
$$

where $R_{i}$ is the binary response of the ith individual concerning whether or not she/he has spent or has considered spending resources on house retrofitting ("revealed information"); $A_{i}$ is the binary response of the ith individual concerning whether or not she/he feels annoyed or very annoyed with wind turbine noise; $\mathrm{SPL}_{\mathrm{i}}$ is the actual wind turbine sound pressure level outside of the dwelling of the $i$ th respondent; $X_{1 i}$ and $X_{2 i}$ are vectors of control variables thought to affect $R_{i}$ and $A_{i}$, respectively.

In the statistical literature, this model is often labelled a recursive (or triangular) simultaneous equation model [22], and is standard practice to estimate (consistently and efficiently) two-equation structural models through the application of ordinary least squares to each equation separately. Three key features of the present analysis, however, render the standard estimation approach inappropriate. In fact: (i) the primary response variable of interest, $R_{i}$, is a binary variable; (ii) one of the important covariates in the first equation, $A_{i}$, is likely to be jointly determined with the response variable $R_{i}$, being a binary variable as well; and, (iii) the assessment of the overall impact of SPL $L_{i}$ on $R_{i}$ requires estimation of both its direct effect as measured in the first equation, and its indirect effect as measured through the effect of $A_{i}$ on $R_{i}$, which is attributable only to changes in SPL

The first of these features requires the use of a suitable modeling technique for binary dependent variables, such as a probit model. Briefly, the probit model estimates the probability that an event occurs (e.g., that $R_{\mathrm{i}}$ takes the unit value) through the construction of an appropriate likelihood function estimable by standard maximum likelihood procedures [23]. The second feature mandates the use of simultaneous equations or structural modeling techniques, whereby the two equations above are jointly estimated. Because $A_{i}$ is a dependent variable in the second (mediating) equation and a predictor of $R_{i}$ in the first (main) equation, a system of equations exists. It is well-known that with such a system of equations, estimating each equation separately is appropriate only if the omitted factors (i.e., the counterparts to error terms in standard linear regression models) in the two equations are 
uncorrelated. This condition, however, is violated if there is an overlap in unobserved characteristics that determine both $A_{i}$ and $R_{i}$.

Consider, for example, any unmeasured characteristic (i.e., a covariate not included in $X_{1}$ and $X_{2}$ above) that increases individuals' propensity to feel more annoyed with WT noise, but simultaneously less inclined or less able to incur in retrofitting actions. Because this characteristic is not explicitly included in the set of explanatory variables, its effect on $A_{i}$ and $R_{i}$ gets subsumed into the error terms of both equations. In particular, the error term in the second (first) equation will take higher (lower) values when this characteristic is present. Because the two error terms will move together, depending on the presence of this characteristic, they will be (negatively, in this example) correlated. Importantly, this example illustrates that a consequence of such across equation correlation between the error terms is that the explanatory (mediating) variable $A_{i}$ will correlate with the error term in the first equation. In fact, if the error terms are correlated, and given that the error term in the second equation partly determines $A_{i}$, then $A_{i}$ is also (negatively) correlated with the error term in the first equation. In this case $A_{i}$ will capture not only the true effect of being annoyed with WT noise but also the effect on $\mathrm{R}_{\mathrm{i}}$ of having this unobservable characteristic. Furthermore, given the negative correlation under consideration, the example illustrates that single estimation of the first equation will suppress any expected positive effect of $A_{i}$ on $R_{i}$, leading to the empirical incorrect conclusion that the mediating effect is weaker than it actually is or that no mediating effect exists when it actually does. The reverse is, of course, also possible, i.e., the existence of positive correlation leading to the conclusion that mediation exists when it actually does not.

Structural modeling techniques solve this problem by explicitly allowing the errors terms across equations to correlate in the model specification, and using full information maximum likelihood methods to estimate the equations as a joint system (e.g., [24]). A difficulty in the present application, however, is that the above system is nonlinear given that both $A_{i}$ and $R_{i}$ are dichotomous variables. This aspect renders familiar simultaneous equations techniques inappropriate. Intuitively, a suitable procedure to address this problem would consist in extending the standard probit model to two equations with correlated error terms. In fact, the so-called bivariate probit model operationalizes this extension (e.g., [22]), and can easily be fit by maximum likelihood methods using, for example, the Stata statistical software (StataCorp. 2015. Stata Statistical Software: Release 14. StataCorp. LP, College Station, TX, USA) [25]. This model is implemented assuming that the error terms have a bivariate standard normal joint distribution with correlation $\rho$, and a likelihood-ratio test can be used to test the hypothesis that the bivariate probit model fits the data better than single-equation univariate probit models. This amounts to testing the null hypothesis that $\rho=0$ against a two-sided alternative; rejection of the null means that joint estimation of the equations is required, whereas failure to reject the null means that the two errors are independent, so that separate estimation of the two structural equations provides consistent estimates of the model's parameters.

Even if the latter turns out to be true (i.e., $\rho$ is not statistically different from zero), this remains a simultaneous equation model, and the third feature above suggests that joint estimation is still warranted (eventually with $\rho$ constrained to equal zero). As has been widely documented [22], the coefficients in a univariate probit model do not measure the marginal effect of the associated explanatory variables on the mean response of the dependent variable, as given by the probability that it takes the unit value. In order to compute marginal effects in this model, one must scale the coefficient by the partial derivative of the expression for the probability that the dependent binary variable takes the unit value with respect to the relevant explanatory variable. While this approach yields the marginal effects of the explanatory variables in the second equation (determining $A_{i}$ ), it fails to measure the total marginal effects of the explanatory variables in the first equation (determining $R_{\mathrm{i}}$ ). Although the computation of these marginal effects in the bivariate probit model is fairly complex [26], it relies on a simple concept: the total marginal effect of a change in a variable in the $R_{i}$ equation must account for the direct effect of a change in that variable on the probability that $R_{i}$ equals one, and for the indirect effect of the change in that variable on the probability that $A_{i}$ equals one in the second 
equation. This, in turn, affects the probability that $R_{i}$ equals one in the first equation. Therefore, the total effect of a marginal change in a variable in the first equation is a sum of these two terms, and the delta method [27] can be used to compute the standard error for this sum in order to assess the statistical significance of the overall marginal effect.

Finally, a concern that arises when estimating a system of equations such as those entailed in the bivariate probit model is that the system must be identified (i.e., there must be enough restrictions in the system to obtain numerical estimates of the structural parameters). As shown by Maddala [23] (p. 122), the conditions for identification in the present model imply that the error terms are independent, or else that there is at least one explanatory variable in the second equation (i.e., in $\mathrm{X}_{2 \mathrm{i}}$ ) not included amongst the explanatory variables in the first equation (i.e., in $\mathrm{X}_{1 \mathrm{i}}$ ). The first condition entails "fixing" the error terms across equations to zero, which, in the context of the present study, is something that should be tested rather than imposed by assumption. The second condition, and the route adopted in the present study, entails finding at least one variable that, on conceptual grounds, directly affects $A_{i}$ but does not directly affect $R_{i}$ and include (exclude) that variable in the second (first) equation. These procedures, therefore, allow us to quantify and test for the full/partial mediation hypotheses while accounting for the possibility that the error terms across equations correlate within the context of a system of binary dependent variables.

\section{Results and Discussion}

\subsection{Overview of Variables Used in the Analyses and Descriptive Statistics}

Detailed information concerning the sound measurements is synthesized in Table 1. As previously indicated, noise measurements were carried out at eight different locations, designated by the initials of the village name ("CD", "L", "VC" and "VP") followed by "high" and "low", corresponding to distinct points in each village, at a high and a low location, respectively. Although the registered WT SPL in Table 1 are relatively lower than those reported in other studies (for example, $[5,28]$ ), it should be noted that the results from different studies cannot be directly compared with one another due to different measurement conditions and possibly different weather situations at the time of the measurements.

Table 1. Summary of noise measurements in the selected villages.

\begin{tabular}{|c|c|c|c|c|c|c|c|c|}
\hline \multirow{3}{*}{ Measurements } & \multicolumn{8}{|c|}{ Topography and Location } \\
\hline & \multicolumn{4}{|c|}{ High } & \multicolumn{4}{|c|}{ Low } \\
\hline & CD & $\mathbf{L}$ & VC & VP & CD & L & VC & VP \\
\hline Mean LAeq-in dB (A) & $45.3(3.6)$ & $42.6(3.1)$ & $46.2(1.0)$ & 41.4 (2.4) & $46.2(5.8)$ & $47.6(3.8)$ & 46.8 (3.9) & $48.0(5.0)$ \\
\hline No. measurements & 9 & 5 & 3 & 5 & 4 & 6 & 3 & 4 \\
\hline
\end{tabular}

Note: Standard deviations are in parentheses. L: Lagoa, CD: Campo Dianteiro, VC: Várzea Cova, VP: Vila Pouca.

The analyses carried out in the present study encompass several types of variables, including variables related to sound and annoyance (noise perception), and to the respondents' opinion about WT, the dwelling characteristics, and the respondents' personal characteristics. A rigorous analysis of the representativeness of the sample is not possible due to lack of information. However, comparing the sample composition with the latest census information available for the biggest village considered in the study (Varzea Cova), it is possible to conclude that the former compares well with the population with respect to age, percentage of females, and schooling years (in 2011, the average age was 48.86, the average number of schooling years was $4.96 \%$, and $51.2 \%$ of the inhabitants were female). The definition of the variables used in the analyses as well as the descriptive statistics (means and standard deviations) both for the overall sample and stratified by individuals' response to the revealed information question are shown in Table 2. 
Table 2. Definition of variables and descriptive statistics.

\begin{tabular}{|c|c|c|c|c|}
\hline \multirow{2}{*}{ Variable } & \multicolumn{2}{|c|}{ Revealed Information } & \multirow{2}{*}{ Overall } & \multirow{2}{*}{ Description } \\
\hline & $\mathbf{R}_{\mathrm{i}}=0$ & $R_{i}=1$ & & \\
\hline \multicolumn{5}{|l|}{ Sound and Annoyance } \\
\hline $\begin{array}{l}\text { Sound (Sound } \\
\text { Pressure Level) }\end{array}$ & $45.22(2.40)$ & $45.85(2.13)$ & $45.45(2.32)$ & $\begin{array}{l}\text { Equivalent continuous Sound Pressure } \\
\text { Level (LAeq, in dBA)-SPL }\end{array}$ \\
\hline Indoors annoyance & 0.22 & 0.52 & 0.33 & $\begin{array}{l}\text { Binary variable, } 1 \text { if annoyed or very } \\
\text { annoyed, } 0 \text { otherwise }\end{array}$ \\
\hline Outdoors annoyance & 0.20 & 0.59 & 0.34 & $\begin{array}{l}\text { Binary variable, } 1 \text { if annoyed or very } \\
\text { annoyed, } 0 \text { otherwise }\end{array}$ \\
\hline \multicolumn{5}{|l|}{$\begin{array}{l}\text { Opinion about Wind } \\
\text { Turbines }\end{array}$} \\
\hline Efficient & 0.47 & 0.38 & 0.44 & $\begin{array}{l}\text { Binary variable, } 1 \text { if efficient or very } \\
\text { efficient, } 0 \text { otherwise }\end{array}$ \\
\hline Inefficient & 0.10 & 0.31 & 0.18 & $\begin{array}{l}\text { Binary variable, } 1 \text { if inefficient or very } \\
\text { inefficient, } 0 \text { otherwise }\end{array}$ \\
\hline Necessary & 0.55 & 0.38 & 0.49 & $\begin{array}{l}\text { Binary variable, } 1 \text { if necessary or very } \\
\text { necessary, } 0 \text { otherwise }\end{array}$ \\
\hline Unnecessary & 0.18 & 0.38 & 0.25 & $\begin{array}{l}\text { Binary variable, } 1 \text { if unnecessary or very } \\
\text { unnecessary, } 0 \text { otherwise }\end{array}$ \\
\hline Landscape positive & 0.37 & 0.38 & 0.38 & $\begin{array}{l}\text { Binary variable, } 1 \text { if positive or very } \\
\text { positive impact, } 0 \text { otherwise }\end{array}$ \\
\hline Landscape negative & 0.14 & 0.28 & 0.19 & $\begin{array}{l}\text { Binary variable, } 1 \text { if negative or very } \\
\text { negative impact, } 0 \text { otherwise }\end{array}$ \\
\hline \multicolumn{5}{|l|}{ Dwelling characteristics } \\
\hline Visibility & 0.76 & 1.00 & 0.85 & $\begin{array}{l}\text { Binary variable, } 1 \text { if WT visible from the } \\
\text { dwelling, } 0 \text { otherwise }\end{array}$ \\
\hline Dwelling age & $42.94(42.62)$ & $45.90(24.21)$ & $44.01(36.87)$ & $\begin{array}{l}\text { Number of years since the since the } \\
\text { dwelling was built }\end{array}$ \\
\hline Topography high & 0.41 & 0.41 & 0.41 & $\begin{array}{l}\text { Binary variable, } 1 \text { if dwelling is located at } \\
\text { a "high" point in the village, } 0 \text { otherwise }\end{array}$ \\
\hline \multicolumn{5}{|l|}{ Personal characteristics } \\
\hline Noise sensitivity & 0.55 & 0.69 & 0.60 & $\begin{array}{l}\text { Binary variable, } 1 \text { if sensitive to noise, } \\
0 \text { otherwise }\end{array}$ \\
\hline Female & 0.51 & 0.52 & 0.51 & Binary variable, 1 if female, 0 otherwise \\
\hline Age & $48.90(19.48)$ & $48.79(19.33)$ & $48.86(19.30)$ & Respondent's age, in years \\
\hline Education & $5.96(3.55)$ & $5.97(3.35)$ & $5.96(3.46)$ & Number of years of schooling \\
\hline Unemployed & 0.10 & 0.17 & 0.13 & $\begin{array}{l}\text { Binary variable, } 1 \text { if unemployed, } \\
0 \text { otherwise }\end{array}$ \\
\hline Economic benefits & 0.22 & 0.07 & 0.16 & $\begin{array}{l}\text { Binary variable, } 1 \text { if benefiting } \\
\text { economically from the turbines, } \\
0 \text { otherwise }\end{array}$ \\
\hline Sample size & 51 & 29 & 80 & Number of respondents \\
\hline
\end{tabular}

Note: $R_{\mathrm{i}}$ takes the unit value if the respondent revealed spending resources on house retrofitting. Standard deviations are in parentheses.

The overall sample is composed of 80 observations, 29 of which correspond to individuals that did spend or have considered spending resources in retrofitting their houses $(R=1)$, and 51 belonged to the group that did not spend or did not considered spending such resources $(R=0)$. A number of differences between these two groups of respondents can be detected. Namely, the proportion of individuals annoyed by wind turbine noise both inside (indoors) and outside (outdoors) their dwelling is higher amongst those who spent or have considered spending resources on house retrofitting (52\% and $59 \%$ in group $\mathrm{R}=0$, compared to $22 \%$ and $20 \%$ in group $\mathrm{R}=1$, indoor and outdoor annoyance, 
respectively). The proportion of individuals holding negative opinions about WT (i.e., that they are inefficient, unnecessary, and/or have a negative impact on the landscape) is also higher amongst the latter group of individuals. In addition, WT are visible from the dwelling of $76 \%$ of the respondents who have not spent nor considered spending resources on house retrofitting, but they are visible from the dwelling of all of the individuals who responded affirmatively to the revealed information question. Likewise, the proportion of individuals reporting being sensitive to noise is higher amongst the latter group of individuals. Conversely, the proportion of individuals benefiting economically from the WT is substantially lower amongst this group.

\subsection{Statistical Determinants of Noise Annoyance and Local Residents' Decision to Take Action}

The statistical analyses herein consider the indoors and outdoors reported annoyance separately since these two annoyance metrics were collected from the applied questionnaire and because it is possible that they can be significantly different. For example, Pedersen and Waye [20] report that only a low number of respondents were annoyed indoors by wind turbine noise. Conversely, Hubbard and Sheppard [29] and Thorne [30] state that people exposed to wind turbine noise inside buildings experience a very different acoustic environment than do those outside, and may be more disturbed by the noise inside their homes than they would be outside namely because the acoustic energy from wind turbines generates structural vibrations and is capable of resonating houses.

In each case, selection of the independent variables in the noise annoyance equation is determined by theoretical considerations and previous research findings. Annoyance due to wind turbine noise is thought to depend on the intensity (SPL) of the sound produced by WT to which individuals are exposed to, and on a number of attitudinal, situational and individual factors. In particular, some research findings suggest that noise-induced annoyance is positively influenced by negative opinions about the source itself [31,32]. Annoyance has also been found to be positively correlated with WT visibility from the respondents' dwellings and with a negative attitude towards the visual impact of WT on the landscape [33-35]. Likewise, visibility and distance from the noise source have been found significant by other authors [36]. This negative attitude is enhanced when the landscape is considered of high aesthetic quality [37]. In addition, noise annoyance has also been shown to depend on terrain and urbanization [38]. Other situational factors possibly influencing annoyance responses are the age of the individuals' dwellings and the topography between the WT and the location of the dwellings. Housing conditions may affect sound transmission and have been previously found to be negatively correlated with the health perception of their residents [39]. As with housing conditions, topography has the potential to alter the auditory sensation and perception of sound pressure levels by, for example, modifying sound propagation, its variability, and/or the sound quality of turbine noise [40].

It should be acknowledged that previous studies have also shown that many other acoustic factors (not considered in the current study) may also play a role on annoyance, especially noise characteristics such as its spectral content or amplitude modulation. In the same way, the noise source visibility issue can be framed in the context of a wider analysis, with emphasis on the way it is perceived and understood by the individual, the so-called soundscape analysis. Previous research in this domain has demonstrated that soundscapes can be described by other equally important descriptors, beyond noise annoyance, e.g., the pleasantness, perceived affective quality, restorativeness, soundscape quality and appropriateness, to name a few [41]. Due to the adopted approach in this study, it should be recognized that the concepts of noise annoyance and the broader concept of soundscape were not fully explored here.

Moreover, evidence shows that annoyance prevalence is also related to personal characteristics of the respondents such as their noise sensitivity, age, and economic conditions, including the possibility to benefit economically from WT [33]. Relatedly, a recent study concluded that support of commercial wind energy depends largely on a belief that wind farms will provide economic benefits to the community [42]. 
With the exception of two identifying restrictions, these attitudinal, situational and individual factors are also included as control variables in the revealed information equation. The first natural identifying restriction is wind turbine visibility from the respondents' dwellings, since it does not vary with their response to the revealed information question. Similarly, the second identifying restriction is the respondent's opinion concerning the visual impact of WT on the landscape. Maximum likelihood estimates of the parameters of the bivariate probit models are reported in Appendix B, and indicate that, taken together, the included explanatory variables are statistically significant determinants of the considered dependent variables. In addition, the estimate of $\rho$ is negative and statistically different from zero in both the Outdoors and Indoors model, implying that the unobserved factors affecting annoyance responses are negatively correlated with those affecting revealed information responses, which vindicates per se the use of the structural estimation techniques adopted in the present analyses.

The estimated marginal effects of the explanatory variables in the two equations of the Indoors model are given in Table 3. The results show that, ceteris paribus, a unit SPL increase enhances the probability of being annoyed by WT noise by 29.3 percentage points (pp). The results also show that annoyance mediates the relationship between SPL and noise reaction as assessed by revealed information responses. In particular, individuals who feel annoyed by wind turbine noise are $38.9 \mathrm{pp}$ more likely to spend resources on house retrofitting than their counterparts who are not annoyed by it at comparable SPL. Noise-induced annoyance, however, does not fully mediate the relationship between sound intensity and noise reaction. In fact, SPL exert an independent positive effect on the likelihood that individuals spend resources on house retrofitting. The total effect of a unit SPL increase on this likelihood is estimated at $23.2 \mathrm{pp}$, where $9.3 \mathrm{pp}$ is the direct effect on the likelihood itself, and $13.9 \mathrm{pp}$ is the indirect effect from the probability of being annoyed attributable only to the unit increase in SPL.

The general opinion of the respondents about WT does not seem to have a significant influence in the reported noise annoyance or in the probability to spend more resources improving their houses. However, the results indicate that those respondents who think that WT are inefficient have a higher probability of being annoyed by noise and, through this effect, to be more willing to spend resources on their houses. Actually, individuals who think that WT are inefficient or very inefficient are $73.1 \mathrm{pp}$ more likely to feel annoyed than those who think otherwise, and this also has an indirect effect on the probability to invest in the houses which is 31.1 pp higher for these individuals.

Falling under the heading of "Dwelling characteristics", all the variables intended to capture situational factors exert a positive and significant effect on self-reported noise annoyance, and through this effect, on the likelihood that individuals spend resources on house retrofitting. In fact, and in line with previous findings by Pedersen [3] and Pedersen and Larsman [43], the results indicate that WT visibility from the respondents' dwellings increases the probability of being annoyed by WT noise by $58.2 \mathrm{pp}$. Likewise, all else the same, respondents living in dwellings located at a "high" point in the village are $57.3 \mathrm{pp}$ more likely to feel annoyed by WT noise than their counterparts living in dwellings located at a "low" point in the village. This result provides strong empirical evidence to the conjecture (e.g., $[38,40])$ that topography impacts the auditory sensation and perception of sound pressure levels, a finding that to the best of our knowledge has not been previously clearly empirically corroborated. The overall effect of WT visibility and topography on individuals' willingness/necessity to spend resources on house retrofitting is estimated at $21.9 \mathrm{pp}$ and $72.5 \mathrm{pp}$, respectively. Ceteris paribus, the effect of the dwellings' age on self-reported noise annoyance, albeit statistically significant, is small in magnitude, with a unit increase in this variable leading to an increase in the probability of annoyance by $0.7 \mathrm{pp}$, and to an indirect increase on the likelihood of investing resources on house retrofitting by $0.2 \mathrm{pp}$. The results also show that both the direct and the overall effect of this variable on house retrofitting efforts are statistically insignificant, a finding that is somewhat surprising given that one would expect that older houses would need more intervention. 
Table 3. Estimated marginal effects: indoors model.

\begin{tabular}{|c|c|c|c|c|c|c|c|c|c|c|c|c|}
\hline \multirow{3}{*}{ Variable } & \multicolumn{9}{|c|}{ Revealed Information } & \multirow{2}{*}{\multicolumn{3}{|c|}{$\begin{array}{c}\text { Annoyance-Indoors } \\
\text { Direct }\end{array}$}} \\
\hline & \multicolumn{3}{|c|}{ Direct } & \multicolumn{4}{|c|}{ Indirect } & \multicolumn{2}{|c|}{ Total } & & & \\
\hline & Estimate & SE & $p$-Value & Estimate & SE & $p$-Value & Estimate & SE & $p$-Value & Estimate & SE & $p$-Value \\
\hline \multicolumn{13}{|l|}{ Sound and annoyance } \\
\hline Sound (SPL) & 0.093 & 0.043 & 0.031 & 0.139 & 0.049 & 0.005 & 0.232 & 0.073 & 0.001 & 0.293 & 0.091 & 0.001 \\
\hline Annoyance & 0.389 & 0.086 & 0.000 & & & & 0.389 & 0.086 & 0.000 & & & \\
\hline \multicolumn{13}{|l|}{ Opinion about WT } \\
\hline Efficient & 0.057 & 0.104 & 0.588 & 0.085 & 0.053 & 0.111 & 0.142 & 0.133 & 0.288 & 0.178 & 0.121 & 0.141 \\
\hline Inefficient & 0.116 & 0.159 & 0.465 & 0.311 & 0.109 & 0.004 & 0.427 & 0.222 & 0.054 & 0.731 & 0.201 & 0.000 \\
\hline Necessary & -0.006 & 0.125 & 0.959 & 0.034 & 0.050 & 0.501 & 0.028 & 0.153 & 0.857 & 0.096 & 0.131 & 0.464 \\
\hline Unnecessary & 0.180 & 0.132 & 0.171 & 0.057 & 0.063 & 0.362 & 0.237 & 0.170 & 0.161 & 0.002 & 0.151 & 0.988 \\
\hline Landscape positive & & & & -0.048 & 0.048 & 0.318 & -0.048 & 0.048 & 0.318 & -0.128 & 0.124 & 0.301 \\
\hline Landscape negative & & & & 0.008 & 0.050 & 0.869 & 0.008 & 0.050 & 0.869 & 0.022 & 0.133 & 0.868 \\
\hline \multicolumn{13}{|c|}{ Dwelling characteristics } \\
\hline Visibility & & & & 0.219 & 0.107 & 0.040 & 0.219 & 0.107 & 0.040 & 0.582 & 0.232 & 0.012 \\
\hline Dwelling age & -0.001 & 0.001 & 0.549 & 0.002 & 0.001 & 0.037 & 0.001 & 0.002 & 0.522 & 0.007 & 0.002 & 0.000 \\
\hline Topography high & 0.388 & 0.184 & 0.036 & 0.337 & 0.133 & 0.011 & 0.725 & 0.258 & 0.005 & 0.573 & 0.265 & 0.031 \\
\hline \multicolumn{13}{|l|}{ Personal characteristics } \\
\hline Noise sensitivity & 0.087 & 0.104 & 0.401 & 0.184 & 0.090 & 0.042 & 0.271 & 0.157 & 0.084 & 0.417 & 0.200 & 0.037 \\
\hline Female & -0.022 & 0.104 & 0.831 & 0.148 & 0.079 & 0.062 & 0.126 & 0.148 & 0.395 & 0.413 & 0.169 & 0.015 \\
\hline Age & -0.001 & 0.004 & 0.825 & 0.003 & 0.002 & 0.163 & 0.002 & 0.005 & 0.652 & 0.008 & 0.005 & 0.083 \\
\hline Education & 0.013 & 0.017 & 0.435 & 0.001 & 0.009 & 0.904 & 0.014 & 0.021 & 0.500 & -0.008 & 0.025 & 0.748 \\
\hline Unemployed & -0.034 & 0.151 & 0.819 & 0.102 & 0.068 & 0.133 & 0.068 & 0.192 & 0.726 & 0.300 & 0.142 & 0.035 \\
\hline Economic benefits & -0.143 & 0.142 & 0.314 & -0.126 & 0.048 & 0.008 & -0.269 & 0.169 & 0.110 & -0.217 & 0.121 & 0.074 \\
\hline
\end{tabular}

Note: SE is the estimate standard error. 
Inspection of the results concerning the effects of respondents' personal characteristics reveals that, ceteris paribus, none of the included variables has a statistically significant overall impact on house retrofitting efforts. However, all things being equal, female and unemployed individuals are, respectively, $41.3 \mathrm{pp}$ and $30.0 \mathrm{pp}$ significantly more likely to feel annoyed by WT noise than their male and non-unemployed counterparts. Consistent with previous results reported in the literature (e.g., [3,33]), noise sensitivity significantly increases the probability of self-reported annoyance with WT noise by $41.7 \mathrm{pp}$. Moreover, the results show that, through the effect on annoyance, noise-sensitive individuals are $18.4 \mathrm{pp}$ more likely to incur in house retrofitting efforts than individuals who do not regard themselves as sensitive to noise. As expected from previous research findings, individuals benefiting economically from the noise source are less likely to report being annoyed by it, but unlike results reported by Pedersen et al. [33], this effect is not statistically significant at less than the 5\% significance level. Importantly, however, this variable exerts a negative and statistically significant indirect effect on house retrofitting efforts. In fact, the results show that, all else the same, respondents who benefit economically from the WT are 12.6 pp less likely to adopt mitigation measures than those who do not benefit from it, a finding that might reflect attempts from the former to curtail any resentment from their non-profiting neighbors thereby hindering any local objections to these projects.

Turning to the analysis of the Outdoors model, the results displayed in Table 4 reveal that the estimates in this model differ little from those in the Indoors model both in sign and statistical significance. Importantly, a noticeable exception to this observation concerns the mean impact of SPL on the probability of annoyance perceived outside the dwelling which is here statistically insignificant. This result stands in stark contrast with the finding concerning the mean impact of SPL on the probability of annoyance perceived indoors and provides strong evidence supporting the claim that wind turbine noise causes greater annoyance in the indoor environment which, in turn, may induce sleep disturbance, stress and other illnesses.

Concerning the impact of outdoors annoyance on noise reaction, the results show that individuals who are annoyed by WT noise when spending time outdoors at the dwelling are 57.3 pp more likely to adopt mitigation measures than those individuals who do not experience outdoors annoyance. As previously found in the Indoors results, however, noise-induced outdoors annoyance does not fully mediate the relationship between sound intensity as measured by SPL and noise reaction. As seen from the results in Table 4, SPL has an independent positive effect on the likelihood that individuals spend resources on house retrofitting, with a unit SPL increase enhancing this likelihood by $13.5 \mathrm{pp}$. The total effect of a unit SPL increase on this likelihood is estimated at $17.9 \mathrm{pp}$, a figure that is lower than the value found in the Indoors model due to the lower indirect (i.e., through its effect on outdoor annoyance) impact of SPL increases on house retrofitting decisions, which is here estimated at $4.4 \mathrm{pp}$.

Taken together, these results are generally in line with existing empirical literature concerning the effects of individuals' characteristics and their opinions about WT on self-reported annoyance due to wind turbine noise. The results also uncover previously untested relationships between topography, noise-induced annoyance, and noise reaction. In particular, the results suggest that terrain separating windfarms from residential property may attenuate the auditory sensation and perception of SPL at comparable turbine visibility conditions and distance, a finding that may account for the mixed results in the literature concerning the impact of WT noise measured in different locations. Furthermore, our results provide the first corroborative evidence for the proposition that people are more disturbed by wind turbine noise inside their homes than they are outside. Notwithstanding, the results also show that annoyance felt both at indoors and outdoors settings mediates the relationship between SPL and noise reaction. Importantly, a key finding from the results in Tables 3 and 4 is that noise-induced annoyance does not fully mediate the relationship between sound intensity and noise reaction, with SPL acting as an independent contributor to individuals' decision to adopt mitigation measures. 
Table 4. Estimated marginal effects: outdoors model.

\begin{tabular}{|c|c|c|c|c|c|c|c|c|c|c|c|c|}
\hline \multirow{3}{*}{ Variable } & \multicolumn{9}{|c|}{ Revealed Information } & \multirow{2}{*}{\multicolumn{3}{|c|}{$\begin{array}{c}\text { Annoyance-Outdoors } \\
\text { Indirect }\end{array}$}} \\
\hline & \multicolumn{3}{|c|}{ Direct } & \multicolumn{3}{|c|}{ Indirect } & \multicolumn{3}{|c|}{ Direct } & & & \\
\hline & Estimate & SE & $p$-Value & Estimate & SE & $p$-Value & Estimate & SE & $p$-Value & Estimate & SE & $p$-Value \\
\hline \multicolumn{13}{|l|}{ Sound and Annoyance } \\
\hline Sound & 0.135 & 0.039 & 0.001 & 0.044 & 0.016 & 0.007 & 0.179 & 0.045 & 0.000 & 0.011 & 0.040 & 0.782 \\
\hline Annoyance & 0.573 & 0.072 & 0.000 & & & & 0.573 & 0.072 & 0.000 & & & \\
\hline \multicolumn{13}{|l|}{ Opinion about WT } \\
\hline Efficient & 0.042 & 0.090 & 0.644 & 0.022 & 0.031 & 0.463 & 0.064 & 0.106 & 0.546 & 0.029 & 0.094 & 0.755 \\
\hline Inefficient & 0.006 & 0.131 & 0.961 & 0.082 & 0.058 & 0.156 & 0.088 & 0.165 & 0.592 & 0.238 & 0.155 & 0.125 \\
\hline Necessary & 0.063 & 0.126 & 0.616 & -0.039 & 0.045 & 0.385 & 0.024 & 0.155 & 0.877 & -0.172 & 0.111 & 0.121 \\
\hline Unnecessary & 0.253 & 0.137 & 0.064 & 0.008 & 0.054 & 0.876 & 0.261 & 0.174 & 0.134 & -0.201 & 0.120 & 0.095 \\
\hline Landscape positive & & & & 0.049 & 0.040 & 0.228 & 0.049 & 0.040 & 0.228 & 0.145 & 0.104 & 0.163 \\
\hline Landscape negative & & & & 0.029 & 0.043 & 0.500 & 0.029 & 0.043 & 0.500 & 0.085 & 0.120 & 0.479 \\
\hline \multicolumn{13}{|c|}{ Dwelling characteristics } \\
\hline Visibility & & & & 0.107 & 0.046 & 0.019 & 0.107 & 0.046 & 0.019 & 0.317 & 0.130 & 0.015 \\
\hline Dwelling age & 0.000 & 0.001 & 0.720 & 0.001 & 0.001 & 0.310 & 0.001 & 0.002 & 0.535 & 0.001 & 0.002 & 0.444 \\
\hline Topography high & 0.372 & 0.173 & 0.031 & 0.193 & 0.072 & 0.007 & 0.565 & 0.208 & 0.007 & 0.242 & 0.166 & 0.145 \\
\hline \multicolumn{13}{|l|}{ Personal characteristics } \\
\hline Noise sensitivity & -0.024 & 0.101 & 0.811 & 0.096 & 0.048 & 0.047 & 0.072 & 0.132 & 0.586 & 0.306 & 0.086 & 0.000 \\
\hline Female & -0.061 & 0.092 & 0.507 & 0.051 & 0.038 & 0.178 & -0.01 & 0.116 & 0.930 & 0.205 & 0.094 & 0.028 \\
\hline Age & -0.001 & 0.003 & 0.856 & 0.001 & 0.001 & 0.334 & 0.0007 & 0.004 & 0.869 & 0.004 & 0.004 & 0.213 \\
\hline Education & 0.009 & 0.016 & 0.572 & 0.012 & 0.006 & 0.046 & 0.021 & 0.020 & 0.281 & 0.028 & 0.017 & 0.093 \\
\hline Unemployed & 0.014 & 0.138 & 0.920 & 0.001 & 0.049 & 0.976 & 0.015 & 0.172 & 0.929 & -0.008 & 0.118 & 0.946 \\
\hline Economic benefits & -0.042 & 0.126 & 0.743 & -0.159 & 0.038 & 0.000 & -0.201 & 0.146 & 0.169 & -0.435 & 0.117 & 0.000 \\
\hline
\end{tabular}

Note: SE is the estimate standard error. 


\section{Conclusions}

Wind farm projects are frequently opposed by local communities on the grounds that residents develop detrimental physiological and psychological symptoms associated with wind turbine noise. Indeed, noise-induced annoyance presently constitutes the primary response variable used in social surveys to evaluate the health effects of noise on people living close to wind turbines. While useful, self-reported annoyance gives us only a relatively simple sense of how people feel about the noise generated by wind turbines. Moreover, authorities' adoption of precautionary and/or compensation measures is, in most cases, based on revealed preference arguments-actions that reveal local residents' perceptions of how grave this environmental hazard is. In particular, individuals' willingness to perform retrofitting improvements in their houses to improve sound isolation is taken as an indication of both their conviction regarding the causal relationship between noise and health outcomes, and the intensity of their noise-induced suffering.

In this paper, we provide a novel research approach to obtaining behavior-based evidence linking wind turbine noise and noise-induced suffering. Specifically, we propose a novel conceptual framework linking WT sound pressure levels, individuals' self-reported annoyance, and their revealed or stated willingness to improve their dwellings. In this framework, WT sound pressure levels may directly affect individuals' decision to implement mitigating actions and/or may indirectly influence that decision through the level of annoyance felt. The proposed framework is empirically evaluated through the application of appropriate structural modeling techniques, and using data collected at a Portuguese wind farm located in a mountain area. In addition, we also address the important challenge of differentiating individuals' noise-induced annoyance when inside their dwellings from that felt when outside their dwellings at the same sound levels. Although both perceptions may impact individuals' well-being and subsequent actions, the former is more clearly associated with adverse health effects such as sleep disturbance and psychological distress. Thus, this study offers two significant advances over previous studies, which have mostly been solely based on subjective annoyance metrics, and evaluated either at indoors or outdoors settings from different respondents.

The key finding from this study is that exposure to wind turbine sound significantly impairs individuals' well-being, because it strongly affects their decision to spend, or consider spending, resources in retrofitting their houses. This effect occurs directly as revealed by exposed individuals' direct behavioral response to wind turbine sound levels, and not just with noise-induced annoyance acting as mediator in that relationship. Thus, although noise annoyance constitutes an adverse effect in itself and is also an indicator of other possible damaging health effects, the results in this study show that more objective data can be useful when assessing the impact of wind turbine sound on individuals' health or well-being, such as individuals' willingness to spend resources to avoid health negative effects or well-being deterioration. The findings of this paper are also relevant at policy level. Firstly, the observed responses provide evidence that the well-being implications of wind farms' installation may be significant. Secondly, because the observed actions entail financial consequences, they could also inform compensation policies for home owners related to costs arising from measures taken to solve or mitigate the undesired sound effects.

Author Contributions: All the authors made a contribution for the conception and design of the study and field work. Hernâni Dias, Carlos Bernardo and Pedro Arezes performed the field data collection. Anabela Botelho performed the data analysis and model conception. Lígia Pinto coordinated the paper writing, which has involved all the authors.

Conflicts of Interest: The authors declare no conflict of interest. 


\section{Appendix A. Questionnaire on Wind Turbine Noise Perception (Adapted from Pedersen \&} Waye [21])

\section{Section I}

1. How satisfied are you with your living environment? (Very satisfied, satisfied, not so satisfied, not satisfied, not at all satisfied)

2. Have there been any changes to the better in your living environment/municipality during the last years? (No, yes! If yes, state what changes)

3. Have there been any changes to the worse in your living environment/municipality during the last years? (No, yes! If yes, state what changes)

4. State for each of the following factors your degree of nuisance when you spend time outdoors at your dwelling: odors from industries (if applicable), odors from fertilizers, insects, fans, noise from wind turbines, railway noise (if applicable), road traffic noise, lawn mowers noise. (Do not notice, notice but not annoyed, slightly annoyed, rather annoyed, very annoyed)

5. State for each of the following factors your degree of nuisance when you are indoors in your dwelling: odors from industries (if applicable), odors from fertilizers, insects, fans, noise from wind turbines, railway noise (if applicable), road traffic noise, lawn mowers noise. (Do not notice, notice but not annoyed, slightly annoyed, rather annoyed, very annoyed)

6. How would you describe your sensitivity to the following factors: air pollution? Odors? Noise? Littering? (Not sensitive at all, slightly sensitive, rather sensitive, very sensitive)

\section{Section II}

1. Are you able to see any wind turbine from your dwelling or your garden? (Yes, No)

2. What is your opinion on the impact of wind turbines on the landscape? (Very positive, positive, neither positive nor negative, negative, very negative)

3. State for each of the following factors how you are affected by wind turbines when you are indoors in your dwelling: shadows from rotor blades? Reflections from rotor blades? Sound from rotor blades? Sound from machinery? Changes in the view? (Do not notice, notice but not annoyed, slightly annoyed, rather annoyed, very annoyed)

4. If you are annoyed by noise, shadows and/or reflections from wind turbines, state how often does this happen? (Never/almost never, a few times per year, a few times per month, a few times per week, daily/almost daily)

5. If you can hear the sound generated by wind turbines, how would you describe that sound and what is your reaction to it: tonal, pulsating/throbbing, swishing, whistling, lapping, scratching/squeaking, low frequency, resounding. (Do not notice, notice but not annoyed, slightly annoyed, rather annoyed, very annoyed)

6. How would you characterize the sound from wind turbines in the following special occasions: when the wind blows from the turbines towards my dwelling, when the wind blows towards the turbines, when the wind is week, when the wind is strong, in warm summer nights? (Less clearly heard, more clearly heard, no difference, do not know)

7. Are you annoyed by sound from wind turbines during any of the following activities: relaxing outdoors, barbecue nights, taking a walk, while gardening, other outdoor activities? (Do not notice, notice but not annoyed, slightly annoyed, rather annoyed, very annoyed)

8. Do you own any wind turbines, or are you involved in wind energy? (No, but I rented a space for wind turbines installation, yes I own one or more turbines, yes I own shares of a company that builds/installs wind turbines, yes I own shares of a company that generates electricity from turbines)

9. What is your general opinion on wind turbines? (Very positive, positive, neither positive nor negative, negative, very negative) 
10. Please mark the adjectives that you think are adequate for wind turbines (efficient-inefficient, environmentally friendly-environmentally harmful, unnecessary-necessary, aesthetically ugly-aesthetically nice, threatening-harmonious)

\section{Section III}

1. Personal data

17.1. Gender

17.2. Age

17.3. Educational background

17.4. Employment situation

2. Data about respondents' dwelling

18.1. Year the dwelling was built?

18.2. If the dwelling construction was later than the wind farm installation, indicate if any mitigation measures in its characteristics were adopted (No, yes. Which?)

18.3. If the dwelling construction was earlier than the wind farm installation, indicate if any mitigation measures in the dwelling characteristics were adopted (No, yes. Which? No, but already felt that need ${ }^{*}$ )

* In this case, please indicate what measures you feel need to be adopted. 


\section{Appendix B.}

Table A1. Estimated bivariate probit models: outdoors and indoors annoyance.

\begin{tabular}{|c|c|c|c|c|c|c|c|c|c|c|c|c|}
\hline \multirow{3}{*}{ Variable } & \multicolumn{6}{|c|}{ Outdoors } & \multicolumn{6}{|c|}{ Indoors } \\
\hline & \multicolumn{3}{|c|}{ Revealed Information } & \multicolumn{3}{|c|}{ Annoyance } & \multicolumn{3}{|c|}{ Revealed Information } & \multicolumn{3}{|c|}{ Annoyance } \\
\hline & Coeff. & SE & $p$-Value & Coeff. & SE & $p$-Value & Coeff. & $\mathrm{SE}$ & $p$-Value & Coeff. & SE & $p$-Value \\
\hline \multicolumn{13}{|l|}{ Sound and Annoyance } \\
\hline Sound (SPL) & 0.624 & 0.193 & 0.001 & 0.082 & 0.207 & 0.692 & 0.341 & 0.174 & 0.050 & 1.872 & 0.732 & 0.011 \\
\hline Annoyance & 2.618 & 0.433 & 0.000 & & & & 1.526 & 0.337 & 0.000 & & & \\
\hline \multicolumn{13}{|l|}{ Opinion about WT } \\
\hline Efficient & 0.184 & 0.414 & 0.656 & 0.168 & 0.505 & 0.739 & 0.200 & 0.395 & 0.613 & 1.139 & 0.789 & 0.149 \\
\hline Inefficient & 0.012 & 0.597 & 0.984 & 1.242 & 0.865 & 0.151 & 0.436 & 0.620 & 0.482 & 4.727 & 1.688 & 0.005 \\
\hline Necessary & 0.299 & 0.577 & 0.605 & -0.945 & 0.611 & 0.122 & -0.009 & 0.483 & 0.986 & 0.552 & 0.929 & 0.553 \\
\hline Unnecessary & 1.190 & 0.621 & 0.055 & -1.035 & 0.658 & 0.116 & 0.700 & 0.523 & 0.181 & 0.008 & 0.976 & 0.994 \\
\hline Landscape positive & & & & 0.829 & 0.574 & 0.149 & & & & -0.898 & 0.786 & 0.253 \\
\hline Landscape negative & & & & 0.486 & 0.625 & 0.437 & & & & 0.121 & 0.854 & 0.887 \\
\hline \multicolumn{13}{|l|}{ Dwelling characteristics } \\
\hline Visibility & & & & 1.625 & 0.705 & 0.021 & & & & 3.852 & 1.560 & 0.014 \\
\hline Dwelling age & 0.002 & 0.006 & 0.730 & 0.006 & 0.008 & 0.490 & -0.003 & 0.006 & 0.566 & 0.044 & 0.015 & 0.003 \\
\hline Topography high & 1.734 & 0.816 & 0.034 & 1.378 & 0.836 & 0.099 & 1.429 & 0.733 & 0.051 & 3.534 & 1.846 & 0.056 \\
\hline \multicolumn{13}{|l|}{ Personal characteristics } \\
\hline Noise sensitivity & -0.088 & 0.447 & 0.844 & 1.633 & 0.550 & 0.003 & 0.327 & 0.405 & 0.420 & 2.739 & 1.400 & 0.050 \\
\hline Female & -0.281 & 0.419 & 0.503 & 1.061 & 0.552 & 0.054 & -0.077 & 0.402 & 0.847 & 2.691 & 1.273 & 0.034 \\
\hline Age & -0.002 & 0.015 & 0.875 & 0.022 & 0.020 & 0.253 & -0.004 & 0.014 & 0.766 & 0.053 & 0.033 & 0.112 \\
\hline Education & 0.041 & 0.072 & 0.571 & 0.146 & 0.094 & 0.120 & 0.049 & 0.066 & 0.464 & -0.066 & 0.144 & 0.647 \\
\hline Unemployed & 0.056 & 0.633 & 0.93 & -0.024 & 0.625 & 0.970 & -0.155 & 0.579 & 0.788 & 1.891 & 1.010 & 0.061 \\
\hline Economic benefits & -0.194 & 0.559 & 0.728 & -2.313 & 0.745 & 0.002 & -0.557 & 0.556 & 0.316 & -1.455 & 0.844 & 0.085 \\
\hline Constant & -30.933 & 9.395 & 0.001 & -9.828 & 9.557 & 0.304 & -17.327 & 8.379 & 0.039 & -100.589 & 36.749 & 0.006 \\
\hline
\end{tabular}




\section{References}

1. Deutch, J.M.; Lester, R.K. Making Technology Work. In Applications in Energy and the Environment; Cambridge University Press: Cambridge, UK, 2004; Chapter 3.

2. Guski, R.; Felscher-Suhr, R.; Schuemer, R. The concept of noise annoyance: How international experts see it. J. Sound Vib. 1999, 223, 513-527. [CrossRef]

3. Pedersen, E. Human Response to Wind Turbine Noise. Perception, Annoyance and Moderating Factors. Doctoral Dissertation, Gothenburg University, Gothenburg, Sweden, 2007.

4. Wolsink, M. Wind power implementation: The nature of public attitudes: Equity and fairness instead of "backyard motives". Renew. Sustain. Energy Rev. 2007, 11, 1188-1207. [CrossRef]

5. Phipps, R. Evidence of Dr. Robyn Phipps, in the Matter of Moturimu Wind Farm Application. Heard before the Joint Commissioners. Palmerston North. Available online: https://docs.wind-watch.org/phippsmoturimutestimony.pdf (accessed on 1 October 2013).

6. Bakker, R.H.; Pedersen, E.; van den Berg, G.P.; Stewart, R.E.; Lok, W.; Bouma, J. Impact of wind turbine sound on annoyance, self-reported sleep disturbance and psychological distress. Sci. Total Environ. 2012, 425, 42-51. [CrossRef] [PubMed]

7. Krogh, C.M.E.; Jeffery, R.D.; Aramini, J.; Horner, B. Wind turbines can harm humans: A case study. In Inter-Noise 2012 Conference Proceedings; Institute of Noise Control Engineering: New York, NY, USA, 2012; pp. 1709-1722.

8. Arezes, P.; Dias, H.; Bernardo, C.A. Implication of Wind Power Generation: Perceptions of People Exposed to Turbine Noise. Environ. Eng. Manag. J. 2015, 14, 2221-2228.

9. Jeffery, R.D.; Krogh, C.M.E.; Horner, B. Industrial wind turbines and adverse health effects. Can. J. Rural Med. 2014, 19, 21-26. [PubMed]

10. Schmidt, J.H.; Klokker, M. Health effects related to wind turbine noise exposure: A systematic review. PLoS ONE 2014, 9, e114183. [CrossRef] [PubMed]

11. Health Canada. Wind Turbine Noise and Health Study. Summary of Results. Government of Canada. Available online: http:/ /www.sustainabledevelopment.ca/wp-content/uploads/2015/07/PhaseVII-Health-Canada-Wind-Turbine-Study-Results-2014.pdf (accessed on 23 March 2016).

12. Onakpoya, I.J.; O'Sullivan, J.; Thompson, M.J.; Heneghan, C.J. The effect of wind turbine noise on sleep and quality of life: A systematic review and meta-analysis of observational studies. Environ. Int. 2015, 82, 1-9. [CrossRef] [PubMed]

13. National Health and Medical Research Council. Evidence on Wind Farms and Human Health. Information paper. Govern of Australia, Canberra, Australia. Available online: www.nhmrc.gov.au/guidelines/ publications/eh57 (accessed on 23 March 2016).

14. Expert Panel on Wind Turbine Noise and Human Health. Understanding the Evidence: Wind Turbine Noise; The Council of Canadian Academies: Ottawa, ON, Canada, 2015.

15. Jalali, L.; Nezhad-Ahmadi, M.R.; Gohari, M.; Bigelow, P.; McColl, S. The impact of psychological factors on self-reported sleep disturbance among people living in the vicinity of wind turbines. Environ. Res. 2016, 148, 401-410. [CrossRef] [PubMed]

16. Pedersen, E. Health aspects associated with wind turbine noise. Results from three field studies. Noise Control Eng. J. 2011, 59, 47-53. [CrossRef]

17. Waye, K.P.; Ohrstrom, W.E. Psycho-acoustic characters of relevance for annoyance of wind turbine noise. J. Sound Vib. 2002, 250, 65-73. [CrossRef]

18. Pedersen, O.W. European environmental human rights and environmental rights: A long time coming? Georget. Int. Environ. Law Rev. 2008, 21, 73-111.

19. McMurtry, R.Y. Toward a case definition of adverse health effects in the environs of industrial wind turbines: Facilitating a clinical diagnosis. Bull. Sci. Technol. Soc. 2011, 31, 316-320. [CrossRef]

20. Phillips, C.V. Properly interpreting the epidemiologic evidence about the health effects of industrial wind turbines on nearby residents. Bull. Sci. Technol. Soc. 2011, 31, 303-315. [CrossRef]

21. Pedersen, E.; Waye, K.P. Perception and annoyance due to wind turbine noise-A dose-response relationship. J. Acoust. Soc. Am. 2004, 116, 3460-3470. [CrossRef] [PubMed]

22. Greene, W.H. Econometric Analysis, 5th ed.; Prentice-Hall: Upper Saddle River, NJ, USA, 2003. 
23. Maddala, G.S. Limited-Dependent and Qualitative Variables in Econometrics; Cambridge University Press: Cambridge, UK, 1983.

24. Prucha, I.R. The variance-covariance matrix of the Maximum Likelihood Estimator in triangular structural systems: Consistent estimation. Econometrica 1987, 55, 977-978. [CrossRef]

25. StataCorp. Stata Statistical Software: Release 11; StataCorp LP: College Station, TX, USA, 2009.

26. Greene, W.H. Gender economics courses in Liberal Arts Colleges: Further results. J. Econ. Edu. 1998, 29, 291-300. [CrossRef]

27. Oehlert, G.W. A note on the delta method. Am. Stat. 1992, 46, 27-29. [CrossRef]

28. Kaldellis, J.K.; Garakis, K.; Kapsali, M. Noise impact assessment on the basis of onsite acoustic noise emission measurements for a representative wind farm. Renew. Energy 2012, 41, 306-314. [CrossRef]

29. Hubbard, H.H.; Sheppard, K.P. Wind Turbine Acoustics. NASA Technical Paper 3057 DOE/NASA/20320-77. Personal Communication, 1990.

30. Thorne, B. Noise Impact Assessment Report Waubra Wind Farm-Mr \& Mrs N Dean; Report No. 1537-Rev 1; Noise Measurement Services PTY: South Brisbane, Australia, 2010.

31. Wolsink, M. Attitudes and expectancies about wind turbines and wind farms. Wind Eng. 1990, 13, $196-205$.

32. Krohn, S.; Damborg, S. On public attitudes towards wind power. Renew. Energy 1999, 16, 954-960. [CrossRef]

33. Pedersen, E.; van den Berg, F.; Bakker, R.; Bouma, J. Response to noise from modern wind farms in the Netherlands. J. Acoust. Soc. Am. 2009, 126, 634-643. [CrossRef] [PubMed]

34. Maffei, L.; Iachini, T.; Masullo, M.; Aletta, F.; Sorrentino, F.; Senese, V.P.; Ruotolo, F. The effects of vision-related aspects on noise perception of wind turbines in quiet areas. Int. J. Environ. Res. Public Health 2013, 10, 1681-1697. [CrossRef] [PubMed]

35. Gibbons, S. Gone with the wind: Valuing the visual impacts of wind turbines through house prices. J. Environ. Econ. Manag. 2015, 72, 177-196. [CrossRef]

36. Lee, S.; Kim, K.; Choi, W.; Lee, S. Annoyance caused by amplitude modulation of wind turbine noise. Noise Control Eng. J. 2011, 59, 38-46. [CrossRef]

37. Molnarova, K.; Sklenicka, P.; Stiborek, J.; Svobodova, K.; Salek, M.; Brabec, E. Visual preferences for wind turbines: Location, numbers and respondent characteristics. Appl. Energy 2012, 92, 269-278. [CrossRef]

38. Pederson, E.; Waye, K.P. Wind turbine noise, annoyance and self-reported health and well-being in different living environments. Occup. Environ. Med. 2007, 64, 480-486. [CrossRef] [PubMed]

39. Bonnefoy, X.; Braubach, M.; Krapavickaite, D.; Ormandy, D.; Zurlyte, I. Housing conditions and self-reported health status: A study in panel block buildings in three cities of Eastern Europe. J. Hous. Built Environ. 2003, 18, 329-352. [CrossRef]

40. Cummings, J. The Variability Factor in Wind Turbine Noise. In Proceedings of the 5th International Conference on Wind Turbine Noise, Denver, CO, USA, 28-30 August 2013.

41. Aletta, F.; Kang, J.; Axelsson, O. Soundscape descriptors and a conceptual framework for developing predictive soundscape models. Landsc. Urban Plan. 2016, 149, 65-74. [CrossRef]

42. Bidwell, D. The role of values in public beliefs and attitudes towards commercial wind energy. Energy Policy 2013, 58, 188-199. [CrossRef]

43. Pedersen, E.; Larsman, P. The impact of visual factors on noise annoyance among people living in the vicinity of wind turbines. J. Environ. Psychol. 2008, 28, 379-389. [CrossRef]

(C) 2017 by the authors. Licensee MDPI, Basel, Switzerland. This article is an open access article distributed under the terms and conditions of the Creative Commons Attribution (CC BY) license (http://creativecommons.org/licenses/by/4.0/). 